\title{
Effect of light intensity and nutrient concentration on growth and pigments of the green microalga Tetraselmis suecica
}

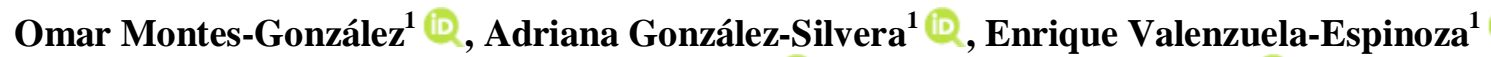 \\ Eduardo Santamaría-del-Ángel ${ }^{1} \mathbb{D}$ \& Jorge López-Calderón ${ }^{1}$ \\ ${ }^{1}$ Universidad Autónoma de Baja California, Facultad de Ciencias Marinas \\ Ensenada, Baja California, México \\ Corresponding author: Adriana González-Silvera (adriana.gonzalez@uabc.edu.mx)
}

\begin{abstract}
Tetraselmis suecica is a green microalga that thrives under a wide range of conditions, used in the commercial culture of fish, mollusk, and crustacean larvae for supplementing the demand for fertilizers. Its pigments have applications in human health care as drug products, vitamins, and cosmetics. Growth and pigment concentration of $T$. suecica were evaluated in experimental cultures with different nutrient concentrations and light intensities to determine the most appropriate culture conditions to optimize the production of biomass and pigments. Chlorophyll- $a$, chlorophyll- $b$, lutein, violaxanthin, $\alpha, \beta$-carotene, and neoxanthin concentrations were evaluated under three different nutrient conditions (441.5/18.1, 883/36.3, and 1766/76.2 $\mu \mathrm{M}$ of $\left.\mathrm{NaNO}_{3} / \mathrm{NaH}_{2} \mathrm{PO}_{4}\right)$ and four light intensities $\left(50,150,300\right.$, and $750 \mu \mathrm{mol}$ quanta $\left.\mathrm{m}^{-2} \mathrm{~s}^{-1}\right)$. Increases in either or both of these factors lead to increases in the concentration of all pigments. Chlorophyll- $a$ reached up to $5 \times 10^{3}$ $\mathrm{mg} \mathrm{m}^{-3}$, chlorophyll- $b$ up to $2500 \mathrm{mg} \mathrm{m}^{-3}$, lutein $600 \mathrm{mg} \mathrm{m}^{-3}$, violaxanthin $300 \mathrm{mg} \mathrm{m}^{-3}, \alpha$, $\beta$-carotene $500 \mathrm{mg} \mathrm{m}^{-3}$, and neoxanthin $400 \mathrm{mg} \mathrm{m}^{-3}$. Growth rate $(\mu)$ attained values of $1.6 \mathrm{~d}^{-1}$. An index to evaluate the efficiency of pigment production by light intensity (called LER) was computed. The highest LER was recorded at $50 \mu \mathrm{mol}$ quanta $\mathrm{m}^{-2} \mathrm{~s}^{-1}$ and a nutrient concentration of $1766 / 76.2 \mu \mathrm{M}\left(\mathrm{NaNO}_{3} / \mathrm{NaH}_{2} \mathrm{PO}_{4}\right)$; this treatment optimizes pigment production with the lowest light intensity. Our results show that the optimum light intensity should be selected according to the objective of the culture, either maximizing pigment concentration for harvesting at higher concentrations or reducing production costs regarding light consumption.
\end{abstract}

Keywords: Tetraselmis suecica; photosynthetic pigments; lutein; nutrients; light intensity; aquaculture

\section{INTRODUCTION}

Tetraselmis suecica is a green microalga in the class Prasinophyceae. It is characterized by possessing welldifferentiated organelles, body size measuring 2-30 $\mu \mathrm{m}$, and flagella covered by rigid scales. Such qualities allow this species to thrive under a wide range of conditions (i.e. nutrients and light) in coastal and oceanic waters (Jeffrey et al. 1997, Barsanti \& Gualtieri 2006, Borghini et al. 2009, Barten et al. 2020). It has been used in the commercial culture of fish, mollusk, and crustacean larvae, as well as for supplementing the demand for fertilizers, drug products, and cosmetics (Contreras et al. 2014, Suganya et al. 2016, Rizwan et al. 2018, Mzozo et al. 2019, Sharawy et al. 2020). The advantage of $T$. suecica for aquaculture lies in its importance as live food for marine species. For example, $T$. suecica has been shown to increase the survival rate, feed conversion rate, protein, and lipids contents in Penaeus vannamei (Sharawy et al. 2020). Also, copepods fed on microalgae shown preference and filled their guts more rapidly than $T$. suecica (Mzozo et al. 2019). For bivalves are the major food source, growing much better in unfiltered seawater with this microalga (Suganya et al. 2016, Rizwan et al. 2018), also complementing with other microalgae ensures the development of the bivalves (Contreras et al. 2014). Furthermore, some phytoplankton pigments contained in this species have applications in human health care. They can be used as food additives and

Corresponding editor: José Luis Iriarte 
supplements, as they function as natural dyes, antioxidants, and some might even serve as anti-cancer agents. For example, the human body uses $\beta$-carotene as a precursor to vitamin $\mathrm{A}$, and lutein is used in ophthalmic treatments to alleviate age-related degenerative damage (Sansone et al. 2017, Faé-Neto et al. 2018, Morançais et al. 2018).

Changes in the pigment composition of microalgae are influenced by environmental factors such as nutrients and light conditions (Borowitzka et al. 2016, Faé-Neto et al. 2018). The addition of nutrients in cultures of Tetraselmis sp. has been evaluated as a means to increase the production of lipids and accessory pigments (Dahmen-Ben et al. 2017, Biondi et al. 2018, Chang et al. 2020). These studies showed that the inhibition of carbohydrate synthesis through modification in the microalgae strain could increase lipid synthesis. Furthermore, nutrient starvation processes lead to oil or carbohydrate accumulation, increased carotenoid contents, and decreased chlorophyll- $a$ (Chl- $a$ ) and chlorophyll- $b$ (Chl- $b$ ) content (Dahmen-Ben et al. 2017). However, the effect of light intensity has been only evaluated, comparing a range from 36 to $133.1 \mu \mathrm{mol}$ quanta $\mathrm{m}^{-2} \mathrm{~s}^{-1}$ (Go et al. 2012). Other works regarding T. suecica have not considered the comparison among different light intensities, and they have only defined one light intensity (Fabregas et al. 1984, Cid et al. 1992, Ulloa et al. 2012, Abiusi et al. 2014). In addition, those intensities ranges are lower than those in natural environments (Coria-Monter et al. 2019); furthermore, the simultaneous effect of light intensity, nitrate, and phosphate has not been considered.

For this reason, this study aims to examine the combined effect of four different light-intensity levels and three nutrient conditions on the growth and pigment composition of $T$. suecica. The study results will support the optimization of culture conditions and contribute to understanding the species response to the varying conditions that it experiences in the ocean.

\section{MATERIALS AND METHODS}

\section{Culture conditions}

Tetraselmis suecica inocula were obtained from the culture collection of the Institute for Oceanological Research (IIO) at Universidad Autónoma de Baja California (UABC) and kept in $\mathrm{f} / 2$ medium (Guillard 1975). We used a two-way factorial experimental design comprising all possible combinations of four light intensity levels $(50,150,300$, and $750 \mu \mathrm{mol}$ quanta $\mathrm{m}^{-2} \mathrm{~s}^{-1}$ ) and three $\mathrm{NaNO}_{3} / \mathrm{NaH}_{2} \mathrm{PO}_{4}$ concentrations (low, 441.5/18.1; medium, 883/36.3; high,
1766/76.2 $\mu \mathrm{M})$. The microalgae were continuously irradiated with daylight fluorescent tubes, and the light intensity was measured with a $4 \pi$ quantum scalar irradiance sensor (Biospherical Instruments model QSL-100). The culture medium was autoclaved at $120^{\circ} \mathrm{C}$ and $1.05 \mathrm{~kg} \mathrm{~cm}^{-2}$ for $15 \mathrm{~min}$. The experiments were carried out in sterile 3-L Erlenmeyer flasks containing $2.9 \mathrm{~L}$ of culture medium; each flask was inoculated with a $200 \mathrm{~mL}$ initial inoculum containing a constant number of cells $\mathrm{mL}^{-1}$ and incubated for seven days at $19 \pm 1^{\circ} \mathrm{C}$; salinity was kept at 33 . Cells were counted daily using a Coulter Multisizer 3 particle counter. The culture growth rate $(\mu$, per day) was calculated using Equation 1:

$$
\mu=\frac{\ln \left(N_{2}\right)-\ln \left(N_{1}\right)}{t_{2}-t_{1}}
$$

where, $\mathrm{N}_{1}$ and $\mathrm{N}_{2}$ are cell densities at the initial $\left(\mathrm{t}_{1}\right)$ and final times $\left(\mathrm{t}_{2}\right)$.

Code names denoting the light intensity $(50,150$, 300 , or $750 \mu \mathrm{mol}$ quanta $\mathrm{m}^{-2} \mathrm{~s}^{-1}$ ) and nutrient concentration level (L: low; M: medium; H: high) are used to refer to the different experimental treatments. For example, $50 \mathrm{~L}$ denotes the treatment with $50 \mu \mathrm{mol}$ quanta $\mathrm{m}^{-2} \mathrm{~s}^{-1}$ and low nutrient concentration.

\section{Analyses of pigments and nutrients}

Samples were taken from each culture daily at the same time of the day over the seven-day culture period to measure pigments and nutrient concentrations. A 5-10 $\mathrm{mL}$ aliquot from each treatment was filtered through a Whatman GF/F $25 \mathrm{~mm}$ filter preserved in liquid nitrogen for subsequent analysis. Pigment concentration was measured using the protocol described by Trees et al. (2003). Each filter was thawed and placed in $4 \mathrm{~mL}$ of $100 \%$ acetone to extract the pigments. Pigments were identified and quantified using high-performance liquid chromatography on an ODS-2 C18 column using a three-solvent gradient system at a flow rate of $1 \mathrm{~mL}$ $\mathrm{min}^{-1}$. Pigment separation took $25 \mathrm{~min}$, and the pigment peaks were detected with a ThermoQuest UV6000 scanning diode-array detector (190 to $800 \mathrm{~nm}$ at $1 \mathrm{~nm}$ resolution). The pigments evaluated were Chl- $a$, Chl- $b$, and the carotenoids lutein (Lut), violaxanthin (Viola), $\alpha, \beta$-carotene (Caro), and neoxanthin ( $\mathrm{Neo}$ ).

Filtrates from the pigment analyses were used for nutrient analysis. They were placed in polypropylene bottles and stored at $-20^{\circ} \mathrm{C}$ in an ultra-freezer until analysis. Nutrient (nitrates and phosphates) concentration was determined with the method described by Parson et al. (1984), using synthetic seawater to dilute each sample sufficiently to allow measuring its nutrient concentration. For nitrates, $0.5 \mathrm{~mL}$ of a concentrated ammonium chloride solution was added to each diluted 
sample, and a $15 \mathrm{~mL}$ aliquot was poured into a reduction column. A solution of $200 \mu \mathrm{L}$ sulfanilamide was added and mixed to the reduced sample, followed by naphthyl ethylenediamine and mixing, before measuring absorbance at $543 \mathrm{~nm}$. For phosphates, 2.5 $\mathrm{mL}$ of a mixture of molybdic acid, ascorbic acid, and antimony-potassium tartrate mixture added. The resulting complex was reduced to yield a blue solution, and its absorbance read at $885 \mathrm{~nm}$ wavelength.

The light-efficiency rate (LER) was calculated to evaluate pigment production efficiency concerning light intensity. LER is defined as the amount of pigment produced per light intensity unit, as follows:

$$
\begin{aligned}
& \text { Light }- \text { efficiency rate }(L E R)= \\
& \frac{\text { Pigment production }\left(\mathrm{mg} \mathrm{m}^{-3}\right)}{\text { Light intensity }\left(\mu \mathrm{mol} \text { quanta } \mathrm{m}^{-2} \mathrm{~s}^{-1}\right)}
\end{aligned}
$$

where, pigment production is the difference between the concentration at the beginning of the experiment (day 1) and the concentration on day 5. Light intensity is the level corresponding to each treatment. Higher values of LER mean a higher light-efficiency rate.

\section{Statistical analyses}

Previous to the analyses, all data (cell density $\mu$, Chl- $a$, Chl- $b$, Lut, Viola, Caro, and Neo) were tested for normality, using a significance level $\alpha=0.05$. Results indicated that none of these variables had a normal distribution, and for this reason, we selected the a priori Kruskal-Wallis nonparametric ANOVA test to evaluate the significance of the differences, also using a significance level $\alpha=0.05$. When this test indicated differences among treatments, a posterior Wilcoxon test was applied (Wilcoxon et al. 1970) to determine which specific treatment was different from another. This test considers pairwise comparisons between all treatments using the seven days of culture, separately for each variable. For each comparison, all the treatment observations were put together in a single set, arranged in increasing order, and ranked, beginning with 1 for the smallest value. The ranks of each treatment were added up, and the statistic $U$ was computed; this value was then compared with the critical value corresponding to $\alpha=0.05$ (Wilcoxon et al. 1970) to identify significant differences between treatments. The statistical tests for each variable are shown in Tables 1-3.

To explore if the nutrient conditions and light intensities used in our experiments produced significant differences in the light-efficiency rate (LER) of each pigment, we conducted multiple comparisons based on a goodness-of-fit test (GOF) with a variance homogeneity model (Zar 2010).

\section{RESULTS}

\section{Cell density and growth rate $(\mu)$}

Cell density in the Tetraselmis suecica cultures was evaluated in terms of the number of cells (Fig. 1a-c). In all treatments, day 1 was an acclimatization stage; between days 2 and 4, the growth increased, and the growth decreased by day 5 . Higher cell densities were attained under higher light intensities and higher nutrient concentrations. For example, cell density never surpassed $12 \times 10^{5}$ cells $\mathrm{mL}^{-1}$ in the $\mathrm{L}$ treatments (Fig. 1a), whereas it reached up to $26 \times 10^{5}$ cells $\mathrm{mL}^{-1}$ in the $\mathrm{H}$ treatments (Fig. 1c). On the other hand, cell density under high light intensity (300 and $750 \mu \mathrm{mol}$ quanta $\mathrm{m}^{-2} \mathrm{~s}^{-1}$ ) reached somewhat higher levels than in the low light-intensity treatments $\left(50\right.$ and $150 \mu \mathrm{mol}$ quanta $\mathrm{m}^{-2}$ $\left.\mathrm{s}^{-1}\right)$. However, despite these general trends, there were no statistically significant differences between treatments than the seven days of culture (KruskalWallis, $\alpha=0.05$ ).

Nitrate and phosphate concentrations declined with time in all treatments, especially under high light intensity (300 and $750 \mu \mathrm{mol}$ quanta $\mathrm{m}^{-2} \mathrm{~s}^{-1}$ ) (Figs. 2a-c and 3a-c). Nitrate was depleted since day 2 in the $\mathrm{L}$ treatments (Fig. 2a), since day 3 in the $M$ treatments (Fig. 2b), and since day 5 in the $\mathrm{H}$ treatments (Fig. 2c). Phosphates were depleted one day earlier than nitrates in all treatments (Fig. 3a-c).

To better visualize the differences between treatments, data for day 2 (Figs. $4 \mathrm{a}-\mathrm{c}$ and $5 \mathrm{a}, \mathrm{c}, \mathrm{e}, \mathrm{g}, \mathrm{i}$ ) and day 5 (Figs. $4 \mathrm{~b}-\mathrm{d}$ and $5 \mathrm{~b}, \mathrm{~d}, \mathrm{f}, \mathrm{h}, \mathrm{j}$ ) were plotted. The growth rate $(\mu)$ values on day 2 tends to be higher than those on day 5 , showing the difference between rapid growth and slow growth. On the other hand, day $2 \mu$ values tend to increase with both nutrient concentration (Fig. 4a) and light intensity, although the differences between nutrient levels at the highest light intensity (750 $\mu$ mol quanta $\mathrm{m}^{-2} \mathrm{~s}^{-1}$ ) were very small. A similar trend is observed on day 5 (Fig. $4 \mathrm{~b}$ ): $\mu$ increases with a nutrient concentration in the high light intensity treatments (300 and $750 \mu \mathrm{mol}$ quanta $\mathrm{m}^{-2} \mathrm{~s}^{-1}$ ), but not so in the low light intensity ones $(50$ and $150 \mu \mathrm{mol}$ quanta $\mathrm{m}^{-2} \mathrm{~s}^{-1}$ ). Despite these general trends, no statistically significant differences were found when the growth curves of the different treatments were compared (Kruskal-Wallis, $\alpha=0.05$ ).

\section{Pigment concentrations}

Chl- $a$ concentrations ranged between 300 and $1100 \mathrm{mg}$ $\mathrm{m}^{-3}$ on day 2 (Fig. 4c) and between 800 and $4500 \mathrm{mg}$ $\mathrm{m}^{-3}$ on day 5 (Fig. 4d), showing a tendency to increase with nutrient concentration and light intensity. The highest Chl- $a$ concentrations were observed on day 5 in 
Table 1. Results from the pairwise comparisons between treatments using the Wilcoxon test for two independent samples. Results for Chl- $a$ concentration are shown in the upper triangle of the matrix; results for Chl- $b$ concentration are shown in the lower triangle. Green cells denote significant differences $(\alpha=0.05)$, white cells denote non-significant differences, black cells separate the two sets of results. Codes names denote the light intensity $\left(50,150,300\right.$, or $750 \mu \mathrm{mol}$ quanta $\left.\mathrm{m}^{-2} \mathrm{~s}^{-1}\right)$ and nutrient concentration level (L: low; M: medium; H: high) as explained in text.

| \begin{tabular}{|l|l|l|l|l|l|l|l|l|l|l|l|l|}
\hline Treatment & $50 \mathrm{~L}$ & $150 \mathrm{~L}$ & $300 \mathrm{~L}$ & $750 \mathrm{~L}$ & $50 \mathrm{M}$ & $150 \mathrm{M}$ & $300 \mathrm{M}$ & $750 \mathrm{M}$ & $50 \mathrm{H}$ & $150 \mathrm{H}$ & $300 \mathrm{H}$ & $750 \mathrm{H}$ \\
\hline $50 \mathrm{~L}$ & & & & & & & & & & & & \\
\hline $150 \mathrm{~L}$ & & & & & & & & & & & & \\
\hline $300 \mathrm{~L}$ & & & & & & & & & & & & \\
\hline $750 \mathrm{~L}$ & & & & & & & & & & & & \\
\hline $50 \mathrm{M}$ & & & & & & & & & & & & \\
\hline $150 \mathrm{M}$ & & & & & & & & & & & & \\
\hline $300 \mathrm{M}$ & & & & & & & & & & & & \\
\hline $750 \mathrm{M}$ & & & & & & & & & & & & \\
\hline $50 \mathrm{H}$ & & & & & & & & & & & & \\
\hline $150 \mathrm{H}$ & & & & & & & & & & & & \\
\hline $300 \mathrm{H}$ & & & & & & & & & & & & \\
\hline $750 \mathrm{H}$ & & & & & & & & & & & & \\
\hline
\end{tabular}

Table 2. Results from the pairwise comparisons between treatments using the Wilcoxon test for two independent samples. Results for carotenoids lutein (Lut) concentration are shown in the upper triangle of the matrix; results for violaxanthin (Viola) concentration are shown in the lower triangle. Green cells denote significant differences $(\alpha=0.05)$, and white cells denote non-significant differences; black cells separate the two sets of results. Codes names denote the light intensity (50, 150,300 , or $750 \mu \mathrm{mol}$ quanta $\mathrm{m}^{-2} \mathrm{~s}^{-1}$ ) and nutrient concentration level (L: low; M: medium; H: high) as explained in text.

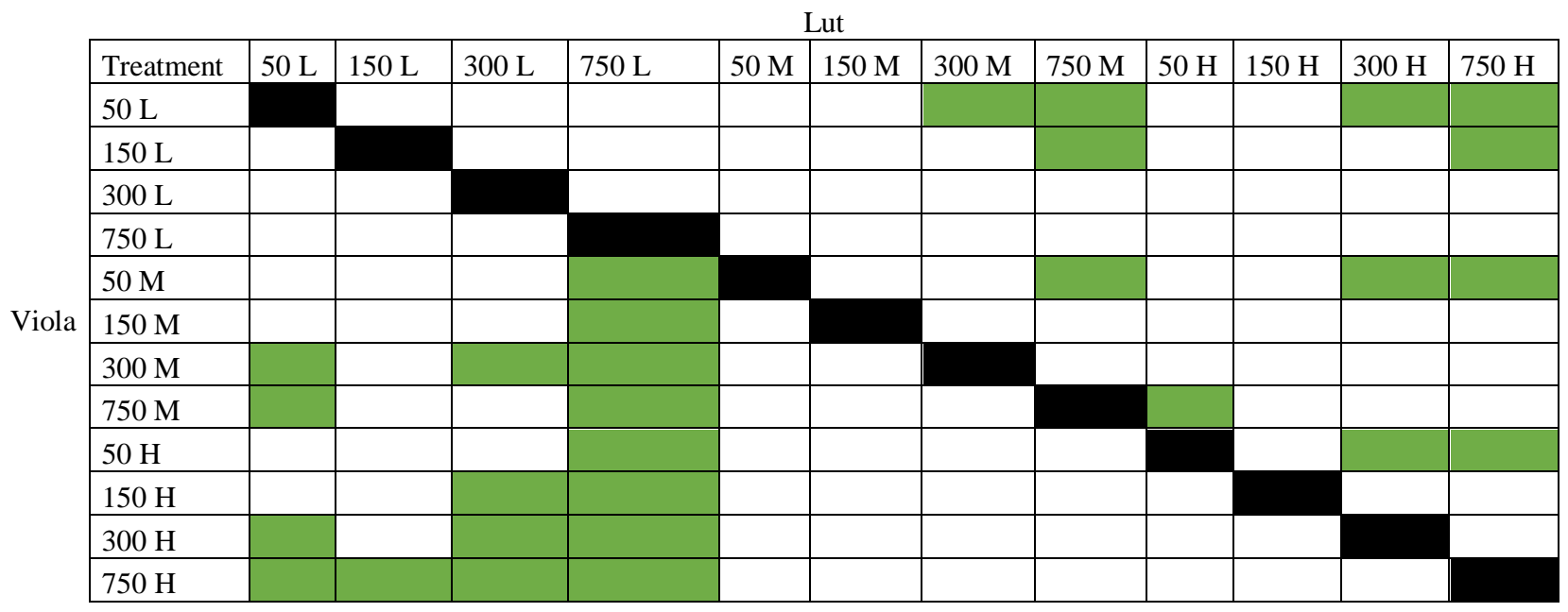

the high nutrient concentration $(\mathrm{H})$ and high light intensity (300 and $750 \mu \mathrm{mol}$ quanta $\mathrm{m}^{-2} \mathrm{~s}^{-1}$ ) treatments. Statistical tests (Table 1) showed significant differences in Chl- $a$ concentration between some treatments; in particular, treatments $\mathrm{H}$ and $\mathrm{M}$ had significantly higher concentrations than treatment $\mathrm{L}$. The same trends were observed for Chl- $b$ (Figs. 5a-b). Chl- $b$ concentrations on day 2 ranged between 100 and $500 \mathrm{mg} \mathrm{m}^{-3}$ and between 200 and $2400 \mathrm{mg} \mathrm{m}^{-3}$ on day 5. Significant differences were observed between $\mathrm{L}$ and $\mathrm{H}$. Chl- $b$ concentrations in treatments 50,150,300, and $750 \mathrm{~L}$ were significantly lower than those in treatments 150 and $300 \mathrm{H}$ (Wilcoxon, $\alpha=0.05$ ). 
Table 3. Results from the pairwise comparisons between treatments using the Wilcoxon test for two independent samples. Results for $\alpha, \beta$-carotene (Caro) concentration are shown in the upper triangle of the matrix; results for neoxanthin (Neo) concentration are shown in the lower triangle. Green cells denote significant differences $(\alpha=0.05)$, white cells denote nonsignificant differences, black cells separate the two sets of results. Codes names denote the light intensity $(50,150,300$, or $750 \mu \mathrm{mol}$ quanta $\mathrm{m}^{-2} \mathrm{~s}^{-1}$ ) and nutrient concentration level (L: low; M: medium; H: high) as explained in text.

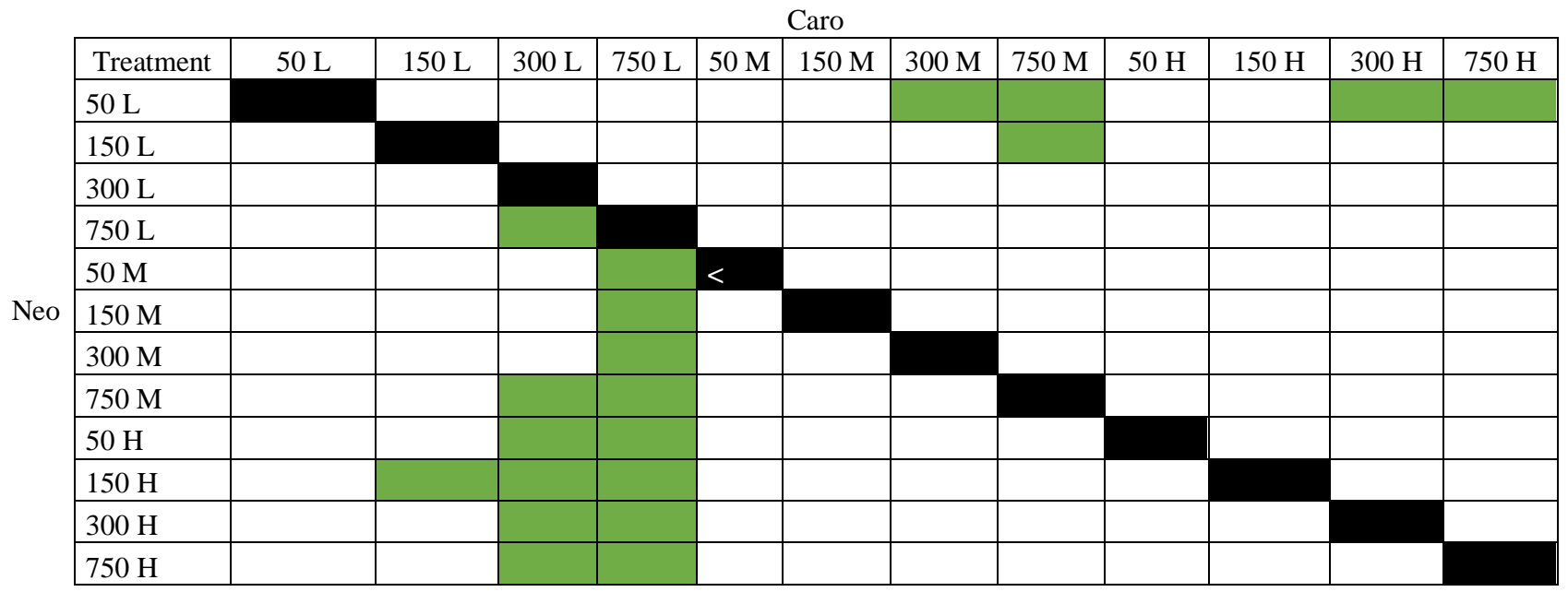

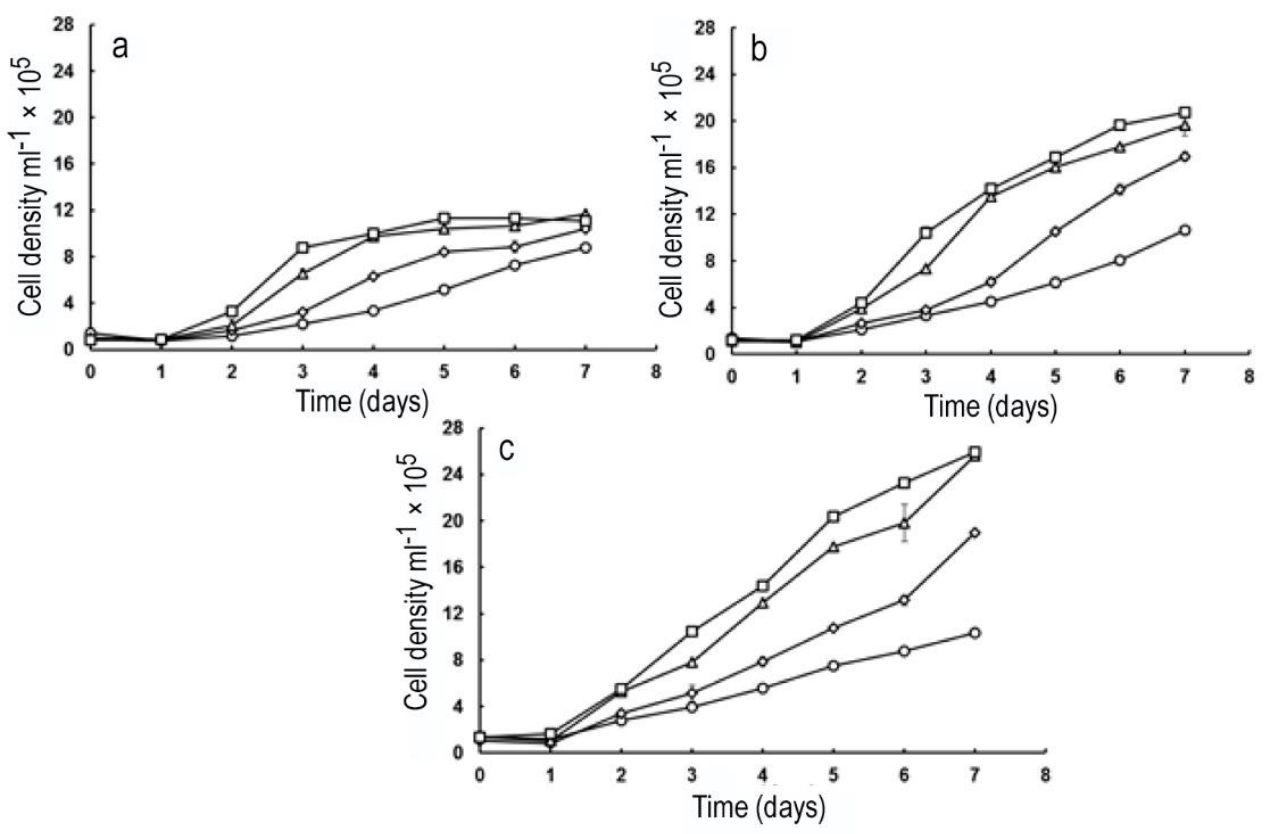

Figure 1. Cell-growth ( \pm standard error) curves of Tetraselmis suecica in culture media with a) low, b) medium, and c)

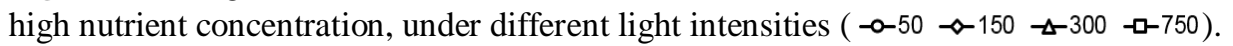

Lut concentrations ranged from 20 to $110 \mathrm{mg} \mathrm{m}^{-3}$ on day two and from 50 to $500 \mathrm{mg} \mathrm{m}^{-3}$ on day 5 , showing a tendency to increase with both nutrient concentration and light intensity (Figs. 5c-d). The highest Lut concentrations were observed on day 5 in the high light intensity treatments (300 and $750 \mu \mathrm{mol}$ quanta $\mathrm{m}^{-2} \mathrm{~s}^{-1}$ ). Statistical tests (Table 2) showed that Lut concentration was significantly higher in the high nutrient concentration-high light intensity treatments (Wilcoxon, $\alpha=$ $0.05)$.

The other pigments followed a similar trend, with their concentration increasing by day 5 . Viola concentrations ranged from 20 to $70 \mathrm{mg} \mathrm{m}^{-3}$ on day 2 and between 50 and $280 \mathrm{mg} \mathrm{m}^{-3}$ on day 5 , with a tendency 

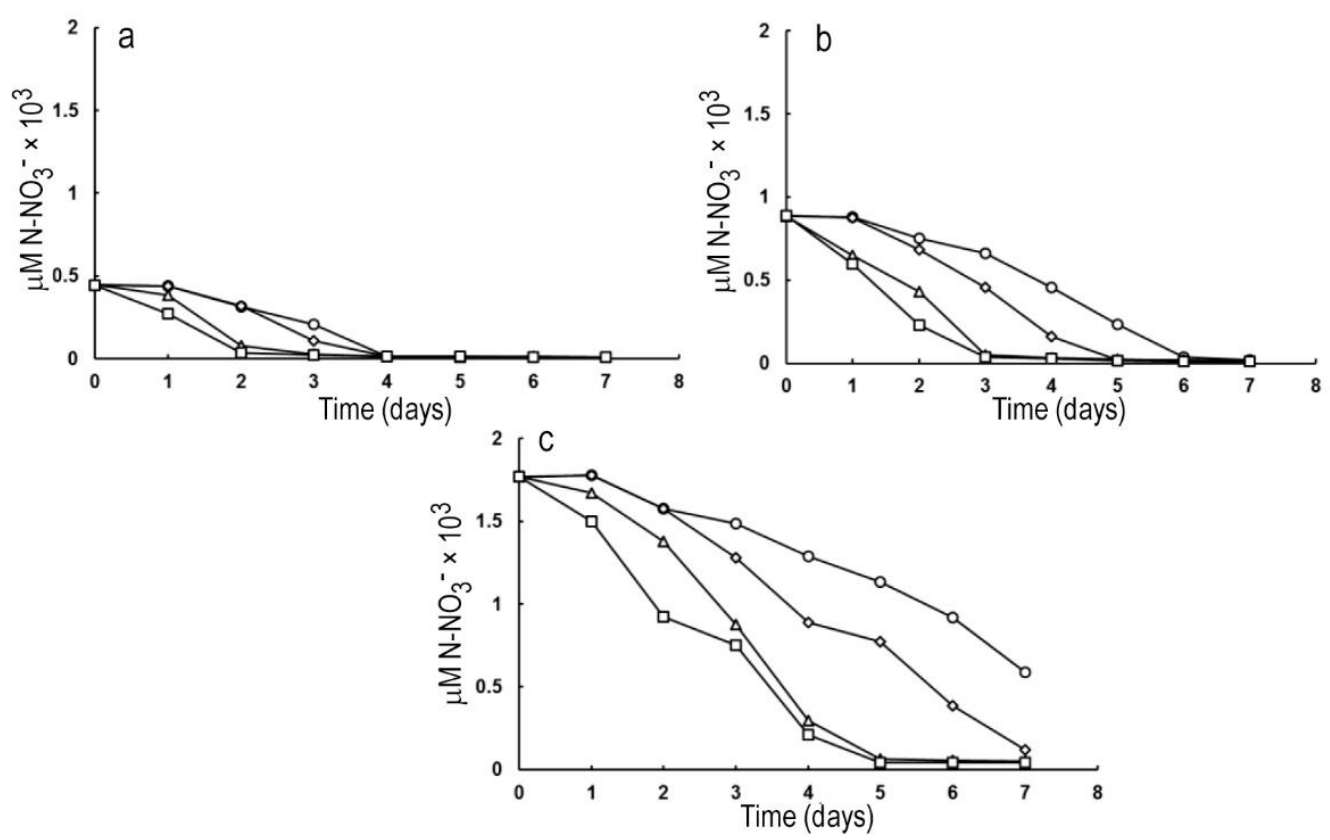

Figure 2. Evolution of nitrate concentration in Tetraselmis suecica cultures with a) low, b) medium, and c) high nutrient

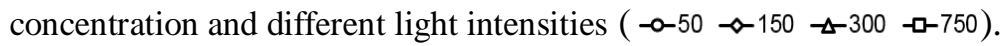
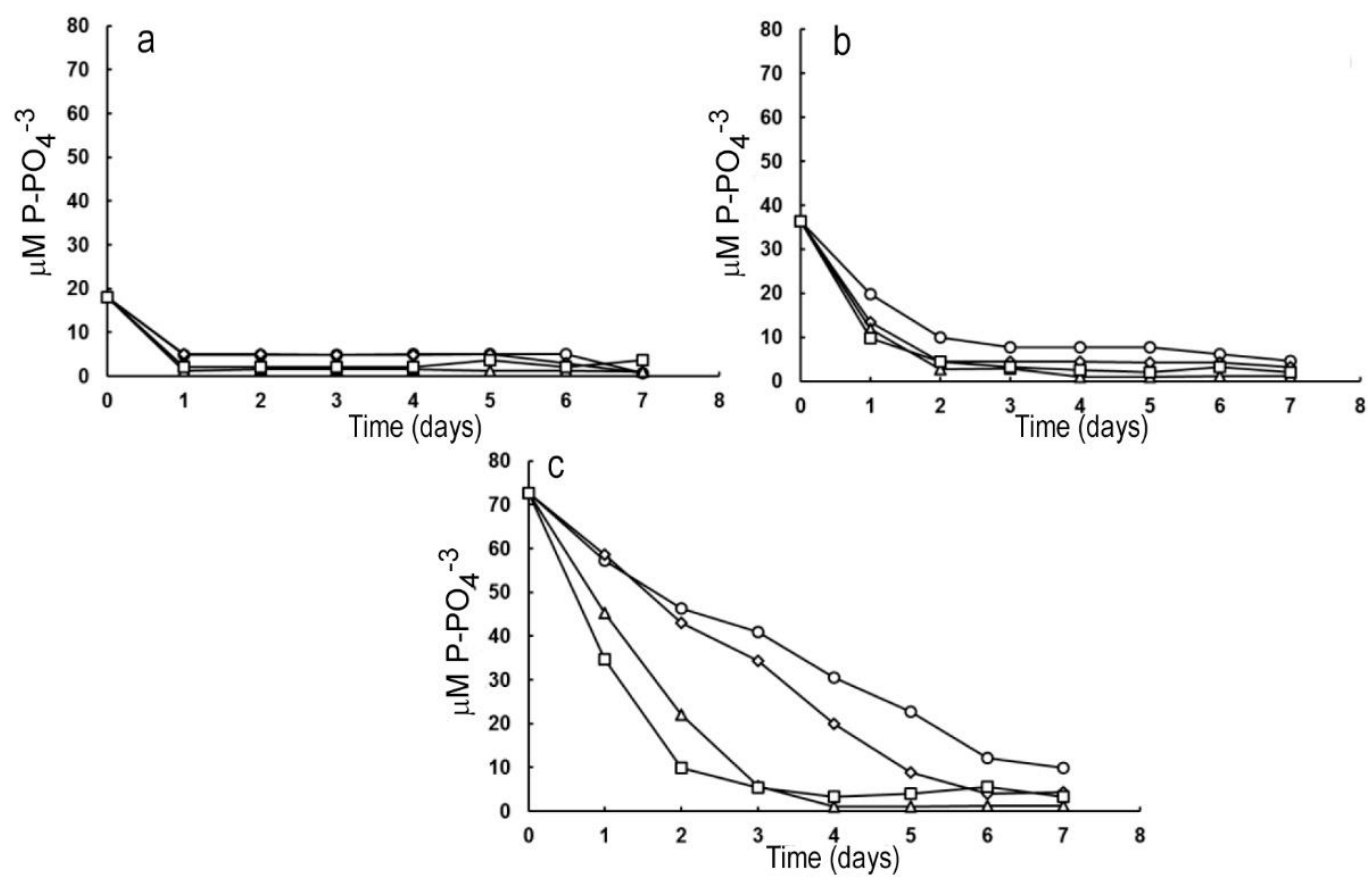

Figure 3. Evolution of phosphate concentration $(\mu \mathrm{M})$ in Tetraselmis suecica cultures with a) low, b) medium and c) high

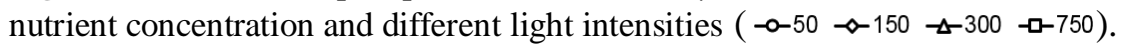

to increase with both nutrient concentration and light intensity (Figs. 5e-f). Statistical tests (Table 2) showed that Viola concentrations in treatments $\mathrm{H}$ and $\mathrm{M}$ were significantly higher than those in treatment $\mathrm{L}$ (Wilcoxon, $\alpha=0.05$ ). Caro concentrations ranged from 10 to $100 \mathrm{mg} \mathrm{m}^{-3}$ on day 2 and from 50 to $480 \mathrm{mg} \mathrm{m}^{-3}$ on day 5 , showing a tendency to increase with both nutrient concentration and light intensity (Figs. 5g-h). The highest Caro concentrations were observed in the high light intensity treatments $(300$ and $750 \mu \mathrm{mol}$ quanta $\mathrm{m}^{-2} \mathrm{~s}^{-1}$ ). Statistical tests (Table 3) showed significant differences in Caro concentrations between 


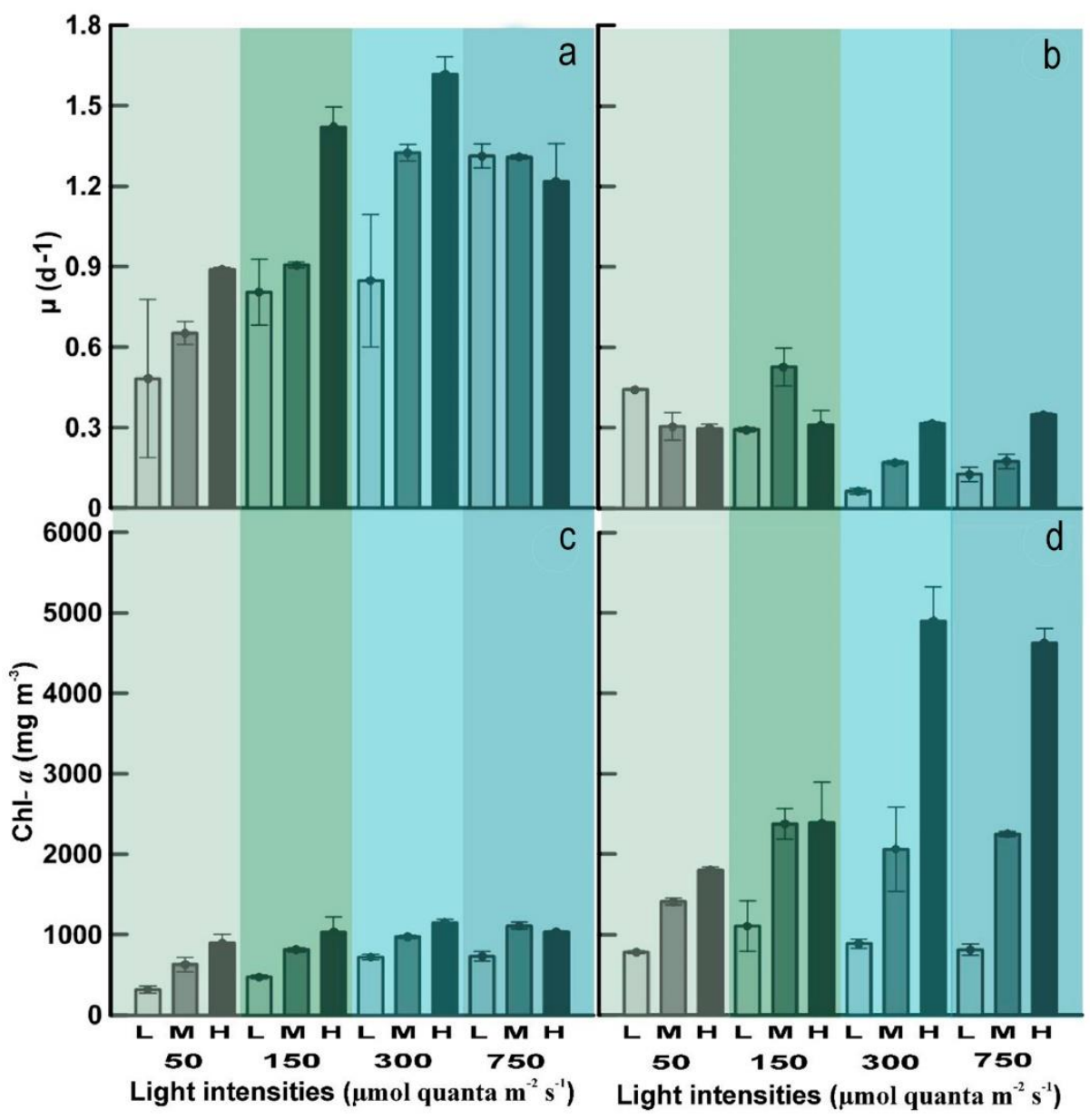

Figure 4. Growth rate $(\mu)$ ( \pm standard error) and Chl- $a$ concentration ( \pm standard error) in Tetraselmis suecica cultures with low (L), medium (M) and high (H) nutrient concentration and different light intensities: a) growth rates on day 2, b) growth rates on day 5, c) Chl- $a$ concentration on day 2 , d) Chl- $a$ concentration on day 5.

the low light-low nutrient concentration treatments and the high light-high nutrient concentration ones (Wilcoxon, $\alpha=0.05$ ). Neo concentrations ranged from 10 to $100 \mathrm{mg} \mathrm{m}^{-3}$ on day 2 and between 50 and $380 \mathrm{mg}$ $\mathrm{m}^{-3}$ on day 5 , with a tendency to increase with both nutrient concentration and light intensity (Figs. 5i-j). The highest Neo concentrations were attained on day 5 in the high light intensity treatments (300 and $750 \mu \mathrm{mol}$ quanta $\mathrm{m}^{-2} \mathrm{~s}^{-1}$ ). Statistical tests (Table 3) showed significant differences in Caro concentrations between some $\mathrm{H}$ and $\mathrm{M}$ treatments and the $\mathrm{L}$ treatment under high light intensity (300 or $750 \mu \mathrm{mol}$ quanta $\mathrm{m}^{-2} \mathrm{~s}^{-1}$ ) (Wilcoxon, $\alpha=0.05$ ).

The LER of pigments in the different treatments (Figs. 6a-f) showed a general trend to increase under lower light intensities and higher nutrient concentrations. The highest efficiencies for $\mathrm{Chl}-a$ were attained in $\mathrm{H}$. In particular, the highest efficiency was observed in the highest nutrient concentration-lowest light intensity treatment $(50 \mathrm{H})$, which was significantly higher $v s$. all others (indicated with an asterisk in Fig. 6a) (GOF, $\alpha=0.05)$. The same pattern was observed for Chl- $b$ (Fig. 6b). The highest LERs for Lut were attained in treatments $50 \mathrm{H}, 150 \mathrm{M}$, and 300 $\mathrm{H}$ (Fig. 6c), with no significant differences (GOF, $\alpha=$ $0.05)$. The highest efficiencies for Viola were observed in treatments $50 \mathrm{M}$ and $50 \mathrm{H}$ (Fig. 6d), with no significant difference between them (GOF, $\alpha=0.05$ ). The highest efficiencies for Caro were observed in treatments $50 \mathrm{M}$ and $50 \mathrm{H}$ (Fig. 6e). Finally, the highest LER for Neo was attained in treatment $50 \mathrm{H}$ (Fig. 5f).

\section{DISCUSSION}

The growth and pigment concentration of microalgae, including Tetraselmis suecica, are influenced by light intensity and nutrient concentration (Borghini et al. 2009). In our study, combinations of high nutrient con- 


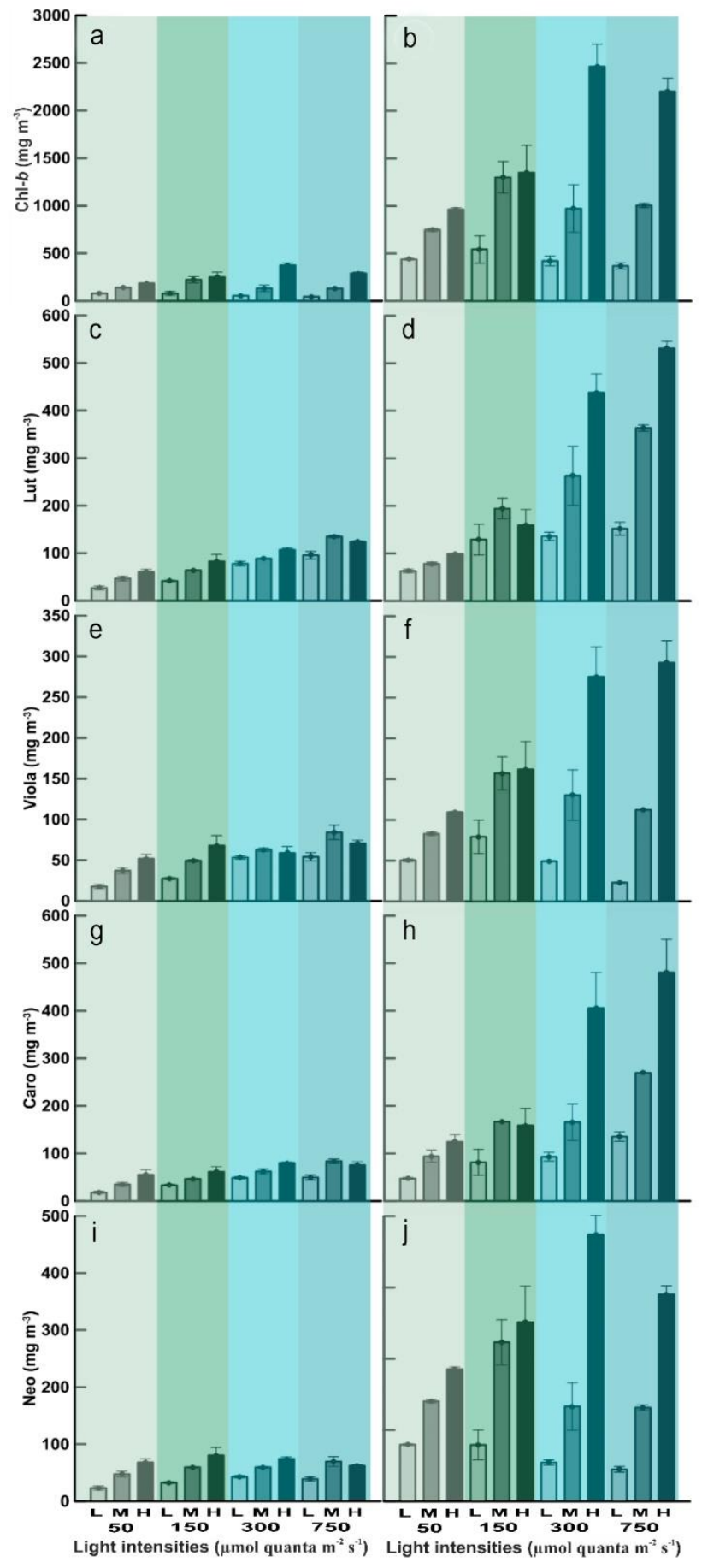

Figure 5. Pigment concentration ( \pm standard error) in Tetraselmis suecica cultures with low (L), medium (M) and high $(\mathrm{H})$ nutrient concentration and different light intensities: a) Chl- $b$ concentration on day 2 ; b) Chl- $b$ concentration on day 5 ; c) carotenoids lutein (Lut) concentration on day $2 ;$ d) carotenoids lutein (Lut) concentration on day 5 ; e) violaxanthin (Viola) concentration on day 2 ; f) violaxanthin (Viola) concentration on day 5 ; g) $\alpha, \beta-$ carotene (Caro) concentration on day 2 ; h) $\alpha$, $\beta$-carotene (Caro) concentration on day 5 ; i) neoxanthin (Neo) concentration on day $2 ; \mathrm{j}$ ) neoxanthin $(\mathrm{Neo})$ concentration on day 5. centration and high light intensity (300 and $750 \mu \mathrm{mol}$ quanta $\mathrm{m}^{-2} \mathrm{~s}^{-1}$ ) provided the most favorable conditions for cell density increase (cell growth). Although there were no statistically significant diffe-rences between treatments, the highest cell densities attained in our cultures $\left(26 \times 10^{5}\right.$ cells $\mathrm{mL}^{-1}$ in the high nutrient concentration-light intensity treatments) were twice as high as the maximum value $\left(13 \times 10^{5}\right.$ cells $\left.\mathrm{mL}^{-1}\right)$ reported by Fabregas et al. (1984) for the same species grown under higher nutrient concentrations but lower light intensities than those used in our study.

Higher nutrient concentrations and higher light intensity favored the growth rate $(\mu)$ of $T$. suecica. The highest $\mu$ values attained in our study (over $1.3 \mathrm{~d}^{-1}$ ) were twice as high as the figure $\left(0.67 \mathrm{~d}^{-1}\right)$ reported by Go et al. (2012) for the same species grown under 108.7 $\mu$ mol quanta $\mathrm{m}^{-2} \mathrm{~s}^{-1}$ and $290 \mu \mathrm{M}$ nitrate. They considered this value as the maximum rate because higher light intensities led to photoinhibition. However, as our results show, $T$. suecica can be grown at higher light intensities of up to $750 \mu \mathrm{mol}$ quanta $\mathrm{m}^{-2} \mathrm{~s}^{-1}$ and thus attain a higher $\mu$. Dahmen-Ben et al. (2017) reported a $\mu$ of $0.6 \mathrm{~d}^{-1}$ for $T$. marina grown under 60 $\mu$ mol quanta $\mathrm{m}^{-2} \mathrm{~s}^{-1}$, while Ulloa et al. (2012) reported a $\mu$ of $0.36 \mathrm{~d}^{-1}$ for $T$. suecica grown under $220 \mu \mathrm{mol}$ quanta $\mathrm{m}^{-2} \mathrm{~s}^{-1}$, and Fabregas et al. (1984) obtained a rate of $0.55 \mathrm{~d}^{-1}$. All these reported rates are about half as high as those attained in our study; this shows that light intensity should be used to attain higher growth rates in cultures. The growth rate is also affected by nutrient concentration, as lower nutrient concentrations are related to lower $\mu$ values. Fabregas et al. (1984) reported that nitrate concentrations of 2000, 4000, and $8000 \mu \mathrm{M}$ are optimal for the growth rate $\left(0.55 \mathrm{~d}^{-1}\right)$ of $T$. suecica, that crop biomass did not increase with higher nutrient concentrations, and that $2000 \mu \mathrm{M}$ was the most efficient concentration. However, the $\mu$ value reported by Fabregas et al. (1984) is half as high as the one attained in our study; this can be explained by the low light intensity $\left(220 \mu \mathrm{mol}\right.$ quanta $\left.\mathrm{m}^{-2} \mathrm{~s}^{-1}\right)$ used by those authors, which is just one-third of the intensity used in our cultures. Therefore, the combined effect of these two variables is specifically important to determine the expected growth rates.

In our study, pigment concentrations also increased with light intensity and nutrient concentration. The highest pigment concentrations were attained under high light intensities (300 or $750 \mu \mathrm{mol}$ quanta $\mathrm{m}^{-2} \mathrm{~s}^{-1}$ ), a finding that should be borne in mind if the culture objective is to produce pigments. Several pigments produced by $T$. suecica have applications in human health care. For example, lutein is used in ophthalmic treatments (Cho et al. 2011) and is an important source 


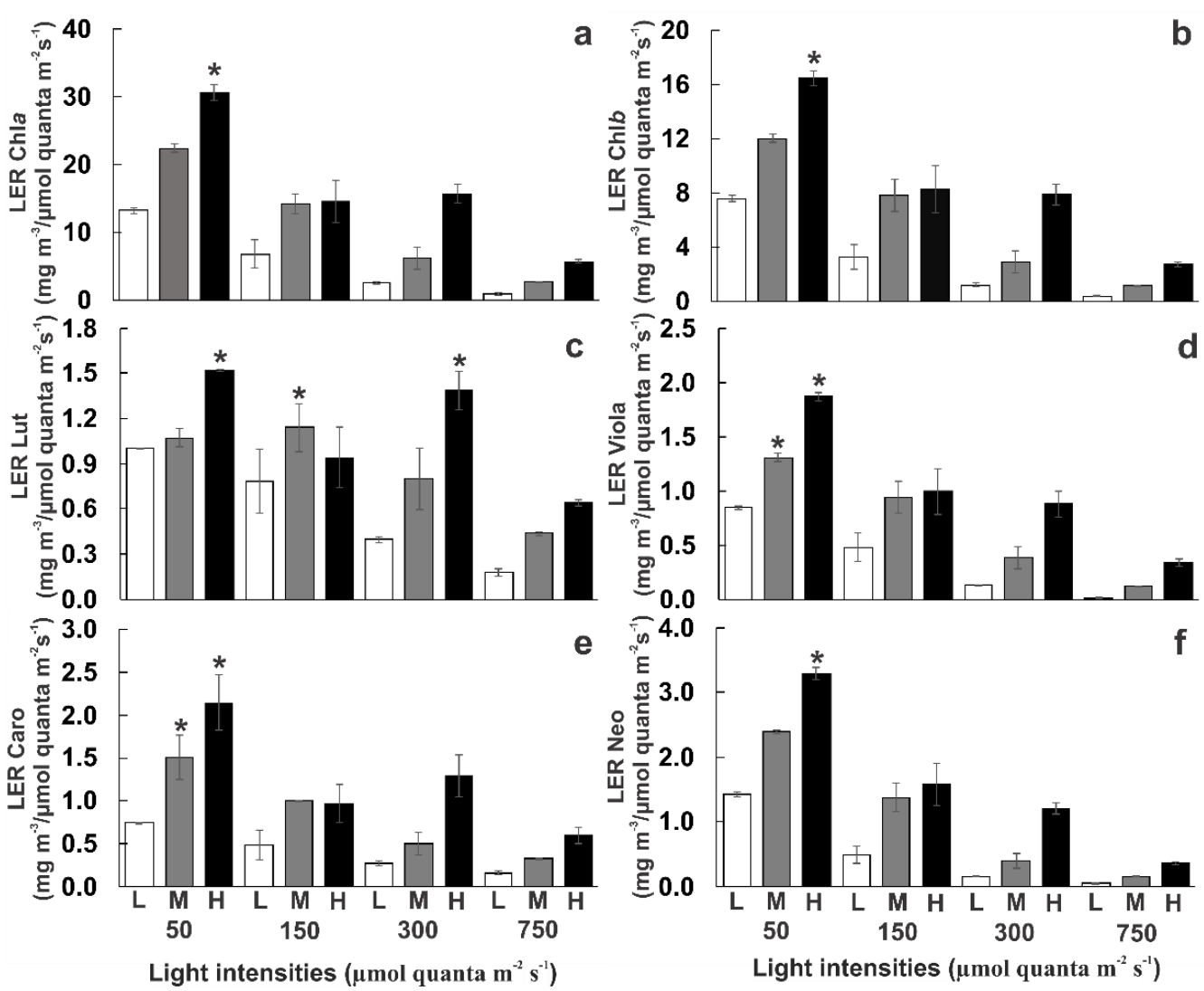

Figure 6. Light-efficiency rate (LER) of pigment production ( \pm standard error) in Tetraselmis suecica cultures with low $(\mathrm{L})$, medium $(\mathrm{M})$ and high $(\mathrm{H})$ nutrient concentration and different light intensities: a) Chl- $a$, b) Chl- $b$, c) carotenoids lutein (Lut), d) violaxanthin (Viola), e) $\alpha$, B-carotene (Caro), f) neoxanthin (Neo). *Indicates statistically significant higher LER values (GOF, $\alpha=0.05)$.

of diet supplements to delay human health decline (Del Campo et al. 2007). In our cultures, Lut and other pigments attained concentrations several orders of magnitude higher than those obtained in other studies on the same species (e.g. Borghini et al. 2009).

Several studies have evaluated various light conditions, seeking to optimize the production and pigments of microalgae. However, most of those studies have focused on the design and behavior of light within bioreactors to increase cell density, and thus improve productivity and reduce costs (Olaru et al. 2015), or increasing the amount of energy produced (in the form of lipids) per total energy consumed (Rattanapoltee \& Kaewkannetra 2014). Our study proposed using the LER to optimize light use and evaluate this ratio for our experimental treatments. The LER is defined as the amount of pigment biomass produced per light unit, thereby identifying the treatment with the best cost-benefit balance. Ahmed (2014) and other authors have used a similar approach to evaluate the protein efficiency rate (in terms of the weight gained from protein consumption) to optimize feed for fish cultures. Evaluating LER provided us with a quantitative tool to identify the culture conditions that best exploit the light resource for producing pigments. In our study, the highest LER -for all the pigments evaluated- was attained in the treatments with the lowest light intensity $\left(50 \mu \mathrm{mol}\right.$ quanta $\left.\mathrm{m}^{-2} \mathrm{~s}^{-1}\right)$, and high nutrient concentrations $(\mathrm{M}$ or $\mathrm{H})$ is the most suitable conditions for pigment production efficiency. Therefore, the lowest light intensity is the most suitable condition in terms of cost-benefit. Some authors (e.g. Coelho et al. 2014, Kawaroe et al. 2016) seek to attain high cell-density production to reduce harvest effort. Therefore, the selection of light-intensity conditions should be based on whether the purpose of the culture is producing a higher pigment concentration or reducing production costs in terms of light consumption.

Based on our experimental results, we conclude that increases in nutrient concentration and light intensity promote a higher concentration of Chl- $a$, Chl- $b$, lutein, violaxanthin, $\alpha, \beta$-carotene, and neoxanthin, which is an advantage for harvesting at higher concentrations. Our 
cultures attained $\mu$ values twice as high as those reported previously, thus showing that light should be adjusted accordingly to promote the required cell growth. However, in terms of light-intensity efficiency (LER), the best treatment was the one with the lowest light intensity $\left(50 \mu \mathrm{mol}\right.$ quanta $\left.\mathrm{m}^{-2} \mathrm{~s}^{-1}\right)$ and a nutrient concentration $\left(\mathrm{NaNO}_{3} / \mathrm{NaH}_{2} \mathrm{PO}_{4}\right)$ of $1766 / 76.2 \mu \mathrm{M}$. Therefore, we conclude that the selection of lightintensity conditions for growing $T$. suecica should be based on whether the objective of the culture is producing pigment in a higher concentration for harvesting at higher concentrations or reducing production costs in terms of light consumption.

\section{ACKNOWLEDGMENTS}

We thank Universidad Autónoma de Baja California and Instituto de Investigaciones Oceanológicas for the internal grants and material support provided for this study. We thank the National Council of Science and Technology for the scholarship awarded to carry out this study (CVU: 400271 Grantee: 261152). María Elena Sánchez-Salazar translated the manuscript into English.

\section{REFERENCES}

Abiusi, F., Sampietro, G., Marturano, G., Biondi, N., Rodolfi, L., D'Ottavio, M. \& Tredici, M.R. 2014. Growth, photosynthetic efficiency, and biochemical composition of Tetraselmis suecica F\&M-M33 grown with LEDs of different colors. Biotechnology and Bioengineering, 111: 956-964.

Ahmed, I. 2014. Dietary amino acid 1-methionine requirement of fingerling Indian catfish, Heteropneustes fossilis (Bloch 1974) estimated by growth and haemato-biochemical parameters. Aquaculture Research, 45: 243-258.

Barsanti, L. \& Gualtieri, P. 2006. Algae anatomy, biochemistry, and biotechnology. CRC Press, Boca Raton.

Barten, R.J.P., Wijffels, R.H. \& Barbosa, M.J. 2020. Bioprospecting and characterization of temperature tolerant microalgae from Bonaire. Algal Research, 50: 102008.

Biondi, N., Cheloni, G., Rodolfi, L., Viti, C., Giovannetti, L. \& Tredici, M.R. 2018. Tetraselmis suecica F\&MM33 growth is influenced by its associated bacteria. Microbial Biotechnology, 11: 211-223.

Borghini, F., Colacevich, A., Bergamino, N., Micarelli, P., Dattilo, A.M., Focardi, S., et al. 2009. The microalgae Tetraselmis suecica in mesocosms under different light regimes. Chemistry and Ecology, 25: 345-357.
Borowitzka, M.A., Beardall, J. \& Raven, J.A. 2016. The physiology of microalgae. Springer International Publishing, Cham.

Chang, K.S., Kim, J., Park, H., Hong, S.J., Lee, C.G. \& Jin, E.S. 2020. Enhanced lipid productivity in AGP knockout marine microalga Tetraselmis sp. using a DNA-free CRISPR-Cas9 RNP method. Bioresource Technology, 303: 122-932.

Cho, Y.C., Cheng, J.H., Hsu, S.L., Hong, S.E., Lee, T.M. \& Chang, C.M.J. 2011. Supercritical carbon dioxide anti-solvent precipitation of anti-oxidative zeaxanthin highly recovered by elution chromatography from Nannochloropsis oculata. Separation and Purification Technology, 78: 274-280.

Cid, A., Abalde, J. \& Herrero, C. 1992. Crecimiento y composición bioquímica de la microalga marine Tetraselmis suecica en cultivos mixotróficos con distintos azúcares y aminoácidos. Cahiers de Biologie Marine, 33: 169-178.

Coelho, R.S., Vidotti, A.D.S., Reis, É.M. \& Franco, T.T. 2014. High cell density cultures of microalgae under fed-batch and continuous growth. Chemical Engineering Transactions, 38: 313-318.

Contreras, R., Pacheco, E. \& Puebla, C. 2014. Desarrollo embrionario y larval temprano de Gari solida (Gray 1828) (Bivalvia: Psammobiidae). Latin American Journal of Aquatic Research, 42: 283-288.

Coria-Monter, E., De León, D.A.S., Monreal-Gómez, M.A. \& Durán-Campos, E. 2019. Optical properties of the waters of the southern Gulf of Mexico during summer. Latin American Journal of Aquatic Research, 47: 568-574.

Dahmen-Ben, I., Chtourou, H., Karray, F., Sayadi, S. \& Dhouib, A. 2017. Nitrogen or phosphorus repletion strategies for enhancing lipid or carotenoid production from Tetraselmis marina. Bioresource Technology, 238: 325-332.

Del Campo, J.A., García-González, M. \& Guerrero, M.G. 2007. Outdoor cultivation of microalgae for carotenoid production: current state and perspectives. Applied Microbiology and Biotechnology, 74: 1163-1174.

Fabregas, J., Abalde, J., Herrero, C., Cabezas, B. \& Veiga, M. 1984. Growth of the marine microalga Tetraselmis suecica in batch cultures with different salinities and nutrient concentrations. Aquaculture, 42: 207-215.

Faé-Neto, W.A., Borges Mendes, C.R. \& Abreu, P.C. 2018. Carotenoid production by the marine microalgae Nannochloropsis oculata in different low-cost culture media. Aquaculture Research, 49: 2527-2535.

Go, S., Lee, S.J., Jeong, G.T. \& Kim, S.K. 2012. Factors affecting the growth and the oil accumulation of 
marine microalgae, Tetraselmis suecica. Bioprocess and Biosystems Engineering, 35: 145-150.

Guillard, R.R.L. 1975. Culture of phytoplankton for feeding marine invertebrates. In: Smith, W.L. \& Chanley, M.H. (Eds.). Culture of marine invertebrate animals. Springer, Berlin, pp. 29-60.

Jeffrey, S.W., Mantoura, R.F.C. \& Wright, S.W. 1997. Phytoplankton pigments in oceanography: guidelines to modern methods. UNESCO, Paris.

Kawaroe, M., Prartono, T., Sunuddin, A. \& Saputra, D. 2016. Marine microalgae Tetraselmis suecica as flocculant agent of bio-flocculation method. Journal of Biosciences, 23: 62-66.

Morançais, M., Mouget, J.-L. \& Dumay, J. 2018. Proteins and pigments. Microalgae in health and disease prevention. Elsevier, Amsterdam, pp. 145-175.

Mzozo, Z.B., Matcher, G.F. \& Vine, N.G. 2019. Aspects of the feeding biology of the copepod Pseudodiaptomus hessei (Copepoda: Calanoida) under culture conditions. Aquaculture Research, 50: 1329-1337.

Olaru, S., Grancharova, A. \& Pereira, F. 2015. Developments in model-based optimization and control. Springer, Berlin.

Parson, T.R., Maita, Y. \& Lalli, C.M. 1984. A manual of chemical and biological methods for seawater analysis. Elsevier, Amsterdam.

Rattanapoltee, P. \& Kaewkannetra, P. 2014. Cultivation of microalga, Chlorella vulgaris under different autohetero-mixo trophic growths as a raw material during biodiesel production and cost evaluation. Energy, 78: 4-8.

Rizwan, M., Mujtaba, G., Memon, S.A., Lee, K. \& Rashid, N. 2018. Exploring the potential of microalgae for new biotechnology applications and beyond: a review. Renewable and Sustainable Energy Reviews, 92: 394-404.

Received: 9 September 2020; Accepted: 18 February 2021
Sansone, C., Galasso, C., Orefice, I., Nuzzo, G., Luongo, E., Cutignano, A., et al. 2017. The green microalga Tetraselmis suecica reduces oxidative stress and induces repairing mechanisms in human cells. Scientific Reports, 7: 41215.

Sharawy, Z.Z., Ashour, M., Abbas, E., Ashry, O., Helal, M., Nazmi, H., et al. 2020. Effects of dietary marine microalgae, Tetraselmis suecica, on production, gene expression, protein markers, and bacterial count of Pacific white shrimp Litopenaeus vannamei. Aquaculture Research, 51: 2216-2228.

Suganya, T., Varman, M., Masjuki, H.H. \& Renganathan, S. 2016. Macroalgae and microalgae as a potential source for commercial applications along with biofuels production: a biorefinery approach. Renewable and Sustainable Energy Reviews, 55: 909-941.

Trees, C.C., Bidigare, R.R., Karl, D.M., Van Heukelem, L. \& Dore, J. 2003. Fluorometric chlorophyll $a$ : sampling, laboratory methods, and data analysis protocols. In: Mueller, J.L., Fargion, G.S. \& McClain, C.R. (Eds.). Ocean optics protocols for satellite ocean color sensor validation. NASA/TM-2003-21621/RevVol 5, Washington, pp. 15-25.

Ulloa, G., Otero, A., Sánchez, M., Sineiro, J., Núñez, M.J. \& Fábregas, J. 2012. Effect of $\mathrm{Mg}, \mathrm{Si}$, and $\mathrm{Sr}$ on growth and antioxidant activity of the marine microalga Tetraselmis suecica. Journal of Applied Phycology, 24: 1229-1236.

Wilcoxon, F., Katti, S.K. \& Wilcox, R.A. 1970. Critical values and probability levels for the Wilcoxon ranksum test and the Wilcoxon signed-rank test. In: Harter, H. \& Bruce, D. (Eds.). Selected tables in mathematical statistics. American Mathematical Society, Providence, pp. 171-259.

Zar, J. 2010. Biostatistical analysis. Prentice-Hall, New Jersey. 